\title{
Cana-de-açúcar: Aspectos econômicos, sociais, ambientais, subprodutos e
}

\section{sustentabilidade}

\author{
Sugarcane: Economic, social, environmental, by-products and sustainability \\ Caña de azúcar: Económica, social, ambiental, subproductos y sustentabilidad
}

Dayane Lilian Gallani Silva

ORCID: https://orcid.org/0000-0002-2267-2794 Universidade Estadual de Maringá, Brasil

E-mail: dayliliga@hotmail.com

Daniella Londero Silva Batisti

ORCID: https://orcid.org/0000-0003-2371-2644 Universidade Estadual de Maringá, Brasil E-mail:dlbatisti@hotmail.com

Maykon José Giacomelli Ferreira ORCID: https://orcid.org/0000-0002-7084-9443 Universidade Estadual de Maringá, Brasil E-mail:maykon.advogado@hotmail.com

Fernanda Bertelis Merlini ORCID: https://orcid.org/0000-0003-0134-801X Universidade Estadual de Maringá, Brasil E-mail:bertelisfer@gmail.com

Ricardo Botelho Camargo ORCID: https://orcid.org/0000-0003-3960-1068 Universidade Estadual de Maringá, Brasil

E-mail:ricardobotelhoc@gmail.com

Beatriz Cervejeira Bolanho Barros ORCID: https://orcid.org/0000-0003-1191-4740 Universidade Estadual de Maringá, Brasil E-mail beatrizbolanho@yahoo.com.br

\begin{abstract}
Resumo
O Brasil é o maior produtor mundial de cana-de-açúcar, sendo assim o objetivo deste trabalho foi apresentar os impactos econômicos, sociais e ambientais do seu cultivo além de mostrar algumas aplicações dos subprodutos gerados no processo de produção com enfoque na sustentabilidade do setor. Para tanto, a metodologia utilizada foi a revisão da literatura disponível em quatro bases de dados: Scielo, CAPES, Science Direct e Google Scholar sobre o tema. Percebese que a indústria sucroalcooleira produz um impacto tanto no setor econômico, social e ambiental. Os subprodutos oriundos do processamento quando bem utilizados podem promover lucros, diminuição dos problemas ambientais e geração de emprego e renda. Porém, é necessário grande investimento tanto do setor público e privado em tecnologias e pesquisas acadêmicas, pois, a utilização dos subprodutos é altamente promissora para o desenvolvimento sustentável permitindo a correta destinação dos resíduos gerados, conduzindo ao caminho promissor do desenvolvimento sustentável.
\end{abstract}

Palavras-chave: Cana-de-açúcar; Subprodutos; Sustentabilidade.

\begin{abstract}
Brazil is the world's largest producer of sugarcane, so the aim of this work was to present the economic, social and environmental impacts of its cultivation, and, to show some applications of the by-products generated in the production process with a focus on the sustainability of the sector. The methodology used was the literature review, available in four databases: Scielo, CAPES, Science Direct and Google Scholar on the topic. It can be seen that the sugar and alcohol industry have an impact on both the economic, social and environmental sectors. By-products from processing when well used can promote profits, reduce environmental problems and generate jobs and income. However, it is necessary to invest more in the public and private sectors in technologies and academic research, since the use of by-products is highly promising for sustainable development, allowing the correct destination of the waste generated, leading to the promising path of sustainable development.
\end{abstract}

Keyword: Sugar cane; By-products; Sustainability. 


\begin{abstract}
Resumen
Brasil es el mayor productor mundial de caña de azúcar, por lo que el objetivo de este trabajo fue presentar los impactos económicos, sociales y ambientales de su cultivo, además de mostrar algunas aplicaciones de los subproductos generados en el proceso productivo con un enfoque en la sostenibilidad del sector. Para ello, la metodología utilizada fue la revisión de la literatura disponible en cuatro bases de datos: Scielo, CAPES, Science Direct y Google Scholar sobre el tema. Se puede ver que el sector del azúcar y el alcohol tiene impactos en los sectores económico, social y ambiental. Los subproductos del procesamiento, cuando se usan bien, pueden promover ganancias, reducir los problemas ambientales y generar empleos y ingresos. Sin embargo, es necesario invertir más en el sector público y privado en tecnologías e investigación académica, ya que el uso de subproductos es altamente prometedor para el desarrollo sustentable, permitiendo el correcto destino de los residuos generados, conduciendo al prometedor camino del desenvolvimiento sustentable.
\end{abstract}

Palabra clave: Caña de azúcar; Subproductos; Sustentabilidad.

\title{
1. Introdução
}

O setor sucroalcooleiro tem grande relevância na economia brasileira, possui um número expressivo de agroindústrias em todas as regiões do país, sendo responsável por gerar milhares de empregos diretos e indiretos. Diante disto, é considerável investigar sob o olhar do desenvolvimento sustentável como o setor impacta na sociedade, na economia e no meio ambiente, e também qual destinação que é dada aos seus resíduos e subprodutos.

Para Machado et al. (2014) é visível a transformação social que a cultura da cana-de-açúcar e a sua industrialização causa em uma sociedade e no ecossistema em que está inserido. Todavia é relevante ressaltar que os impactos gerados, sejam positivos ou não, são derivados de um conjunto de fatores, seja cultural ou ambiental. Segundo Neto et al. (2014) a inovação no setor faz com que a utilização dos subprodutos da cana-de-açúcar possa minimizar os impactos ao meio ambiente, por dar uma destinação correta aos resíduos, como a utilização da vinhaça para a fertilização do solo e do bagaço da cana para a geração de energia, e pode gerar benefícios sociais, tais como empregos e disponibilização de novos produtos para a sociedade.

O aproveitamento da cana-de-açúcar na sua totalidade é um fator primordial para a sustentabilidade do processo de produção do complexo sucroalcooleiro. Esta cultura tem se mostrado como uma das matérias-primas mais importantes da atualidade devido a diversidade do uso de seus produtos e subprodutos.

A utilização dos subprodutos da cana-de-açúcar na indústria de alimentos, na produção de etanol de segunda geração, na construção civil e produção de energia elétrica são algumas opções do uso desses resíduos que abordamos neste artigo. Percebe-se que a utilização destes subprodutos tem um reflexo na viabilidade econômica, no fluxo de processos, na sustentabilidade e nos impactos ambientais.

O presente trabalho se justifica pela importância do setor sucroalcooleiro para a economia, faz uma abordagem dos impactos ambientais e sociais, além de apresentar dados recentes e relevantes para o momento atípico que passa a economia mundial, especialmente de como o setor poderá ser afetado com a pandemia do novo coronavírus. Este artigo objetiva também apresentar uma revisão de trabalhos e publicações significativas que mostram o reaproveitamento dos resíduos gerados nas indústrias de produção de álcool e açúcar e como estes subprodutos são utilizados para geração de novos produtos, com enfoque no desenvolvimento sustentável.

\section{Metodologia}

A pesquisa bibliográfica para este estudo foi realizada por meio de revisão da literatura de natureza qualitativa, sendo que segundo Pereira et al. (2018, p. 67) a interpretação dos autores é fundamental, seguindo um processo indutivo sobre o estudo. Foram utilizadas quatro bases de dados: Scielo, CAPES, Science Direct e Google Scholar, onde os artigos selecionados foram publicados entre janeiro de 1998 a junho de 2020. Quanto ao idioma, foram consideradas as publicações em português, inglês e 
espanhol. Também foram utilizados documentos oficiais (programas de governo, leis), bem como as notícias relativas ao assunto em portais, sites de relevância sobre o tema.

Considerando as diferenças de nomenclaturas utilizadas na indexação nas bases de dados bibliográficas, os termos de busca utilizados foram: cana-de-açúcar, subprodutos cana-de-açúcar, resistência do concreto, cinza de bagaço de cana-de-açúcar; sejam estes associados ou isolados.

\section{Discussão}

\subsection{Produção de açúcar e etanol: histórico e atualidades}

A cana-de-açúcar foi introduzida no Brasil por Martim Afonso de Sousa em sua expedição (1530-1532), dando início a um negócio bem-sucedido. A cana-de-açúcar é uma planta do gênero Saccharum e da família Graminae, o clima ideal para seu cultivo tem duas estações bem definidas: uma quente e úmida para o desenvolvimento vegetativo e outra fria e seca para maturação e acúmulo de sacarose no caule. Os principais produtos obtidos dessa cultivar são açúcar e álcool etílico (etanol). O auge da produção de etanol ocorreu na década de 70 com a crise do petróleo e após cinco anos o governo lançou o Programa Nacional do Álcool (Proálcool) com o objetivo de substituir os veículos a gasolina por álcool e também diante da necessidade de utilização de energia limpa e renovável.

O setor sucroalcooleiro contribui significativamente no Produto Interno Bruto (PIB) brasileiro sendo de grande importância para o país (Carvalho et al., 2013). Segundo afirmações de Jaime Finguerut, diretor do Instituto de Tecnologia Canavieira (ITC) na abertura do workshop Sugar \& Ethanol Brazil em 2019, o setor sucroenergético representa 2\% do PIB brasileiro, mostrando o peso deste setor para a economia. Estes $2 \%$ equivalem a $10 \%$ do valor total bruto do agronegócio, que por sua vez representa 20\% do PIB do Brasil. Este peso pode ser confirmado na geração de mais de 800 mil empregos. O diretor revela que o setor sucroalcooleiro tem salários maiores que os da média do Brasil e o nível de formalização de empregos é maior que a média do agronegócio (Jornalcana, 2019).

A agroindústria sucroalcooleira brasileira trabalha de forma sustentável preocupando-se com o meio ambiente e os efeitos indesejáveis da utilização dos combustíveis fósseis que traz efeitos prejudiciais ao aquecimento global. Por isso, a produção de etanol oferece ao mercado um combustível obtido através de fontes renováveis, ecologicamente correto e que não afeta a camada de ozônio. Além da produção de etanol e açúcar, que são os principais produtos da cana-de-açúcar, muitas unidades industriais estão aumentando sua eficiência produzindo energia elétrica, reduzindo consequentemente os custos e ampliando a sustentabilidade do setor. $\mathrm{O}$ aumento da demanda mundial por etanol, juntamente com as grandes áreas de produção e ótimas condições climáticas, tornam o Brasil um participante competitivo no comércio mundial (Conab, 2019).

Como pode ser observado na Figura 1, a produção brasileira de etanol é geralmente realizada em unidades industriais que também produzem açúcar, existindo assim uma forte interação entre os dois processos de produção que utilizam os mesmos equipamentos de extração (Aquino et al., 2014). Pode-se perceber que durante a produção de açúcar e álcool, ocorre a geração de resíduos, os quais podem seguir diferentes destinos, como será abordado adiante.

\subsection{Impactos Sociais da Indústria Sucroalcooleira}

Barbosa et al. (2012) alegam que a demanda por cana-de-açúcar está em crescente expansão, portanto, a indústria sucroalcooleira vem investindo em novas unidades, tecnologias e infraestrutura, pois além da grande demanda por seus produtos ainda há a demanda social por esse setor se tornar mais sustentável. No sentido de energia renovável e sustentabilidade, o etanol é um combustível que tem uma importância estratégica no combate ao efeito estufa e às mudanças climáticas, pois com a sua baixa emissão de carbono alinha-se aos princípios do desenvolvimento sustentável. 
Com o aumento do consumo de açúcar e etanol, o estado de São Paulo, maior produtor nacional, está com as suas áreas de plantio saturadas. Nesse sentido, faz-se necessário a expansão dessa cultura pelo território brasileiro, avanços tecnológicos, melhoria da infraestrutura e ganho de produtividade por área plantada. $\mathrm{O}$ avanço do setor sucroalcooleiro auxilia no crescimento do PIB nas cidades produtoras de cana-de-açúcar. Embora o plantio esteja presente em muitos municípios, é importante destacar que o ganho econômico tem maior impacto naqueles em que as usinas estão instaladas. Por outro lado, a expansão das lavouras de cana-de-açúcar vem despertando muita preocupação em relação à degradação do solo, alteração da biodiversidade, utilização da água e segurança alimentar. Assim, é necessário aumentar os estudos que indiquem os impactos socioambientais da incorporação da plantação canavieira em diferentes regiões do país (Oliveira; Ferreira; Araújo, 2012). 
Figura 1. Fluxograma de Produção de Açúcar e Etanol.

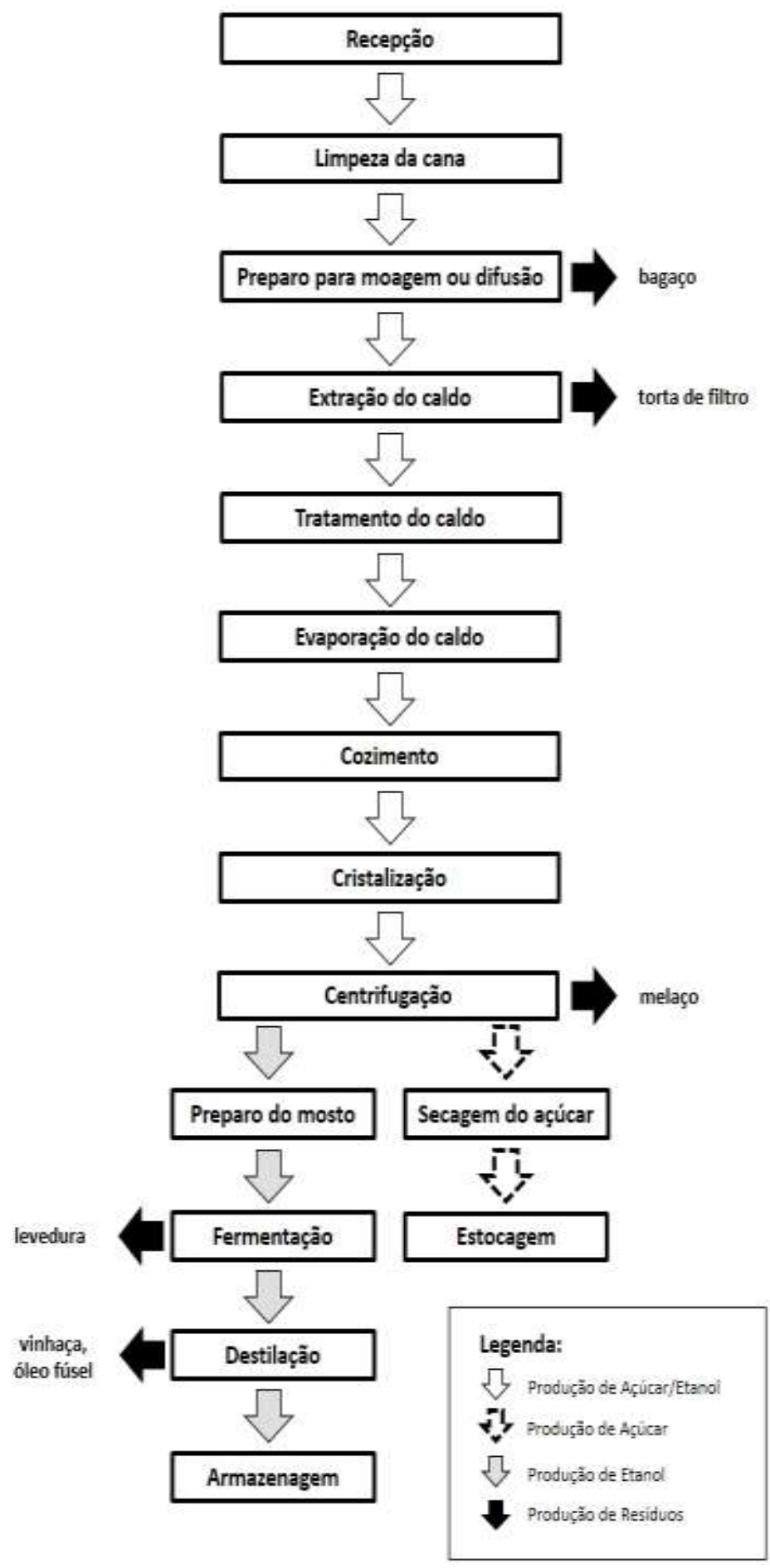

Fonte: Gomes et al. (2016).

As lavouras de cana podem acarretar muitos impactos ambientais, pois as práticas industriais e agropecuárias utilizam agrotóxicos, adubos sintéticos, entre outros agentes que poluem e geram degradação, comprometendo a biodiversidade e o bioma, onde as unidades fabris e as fazendas de produção estão instaladas. Dessa forma, os avanços tecnológicos, a atualização da legislação e a conscientização dos gestores do setor constituem mecanismos para o seu desenvolvimento sustentável. 
Há uma corrente contra o plantio de cana, afirmando que a cultura é muito nociva ao meio ambiente. Vale ressaltar que esse fato é verídico se analisar tempos remotos, em que não havia insumos tecnológicos, legislação de controle ambiental e pouca consciência dos stakeholders, fatores que dificultavam a minimização dos impactos socioambientais desse setor. Por outro lado, estudos indicam que o setor sucroalcooleiro como gerador de renda, empregos, energia com baixo grau de poluição é um instrumento de crescimento local e regional. É importante observar que algumas dessas vertentes são extremistas, e/ou, tendenciosas, sendo preciso avaliar o setor sucroalcooleiro de forma holística, enxergando o todo, desde os impactos que ainda acarretam ao meio ambiente e também os benefícios que geram para a sociedade, sempre visando o desenvolvimento sustentável (Scheuer \& Neves, 2017).

Segundo Liboni e Cezarino (2012) é muito complexo conciliar desenvolvimento socioeconômico e preservação ambiental. Há regiões em que o monitoramento de áreas é realizado através de satélites visando proteger áreas mais vulneráveis. É inegável os impactos sociais do setor na região onde está instalada, por meio da geração de empregos, aumento do PIB, entre outros fatores. Porém, um desafio é superar as custas desse desenvolvimento, tendo em vista as condições precárias dos trabalhadores que atuam no corte de cana, atividade essa que está sendo substituída pela mecanização, forma de colheita que gera empregos com maior qualidade de trabalho e remuneração. Todavia, essas funções não conseguem absorver grande parte dos cortadores envolvidos no trabalho manual, o que poderá acarretar no aumento do desemprego. Isso poderia ser revertido caso treinamentos e cursos de capacitação fossem ofertados, visando a realocação desses trabalhadores em outras funções no setor sucroalcooleiro.

\subsection{Impactos ambientais e da legislação aplicada}

No que diz respeito mais especificamente à questão ambiental, não há como desconsiderar os impactos ambientais e a legislação ambiental aplicável ao meio ambiente. De acordo com Henkes (2009) a preocupação com o meio ambiente é existente desde a edição da Lei Federal no 6.938 de 31 de agosto de 1981, anterior à Constituição Federal vigente, que é de 05 de outubro de 1988. A referida Lei Federal afirma em seu art. $2^{\circ}$ que a Política Nacional do Meio Ambiente tem por objetivo "a preservação, melhoria e recuperação da qualidade ambiental propícia à vida, visando assegurar, no País, condições ao desenvolvimento socioeconômico".

Na temática sobre o meio ambiente é importante destacar que segundo Santos et al., (2016) "a adoção de novas estratégias nas políticas públicas tem como finalidade oferecer benefícios para a preservação do meio ambiente".

A preocupação com o meio ambiente ganhou maior atenção, segundo os mesmos autores, com a ECO-92:

Os questionamentos realizados em prol as questões ambientais tiveram destaque após a Conferência das Nações Unidas sobre Meio Ambiente e Desenvolvimento, Rio-92, com a discussão sobre os impactos do desenvolvimento nos ecossistemas e na saúde da população (Santos et al., 2016).

Corrobora Colombo (2007) "aquele que exerce uma atividade potencialmente poluidora ou que implique risco a alguém assume a responsabilidade pelos danos oriundos do risco criado", sendo, portanto, uma necessidade a observâncias às leis.

A Lei Federal no 12.305 publicada em 02 de agosto de 2010, conhecida como a Política Nacional de Resíduos aos Resíduos Sólidos é um importante marco no que diz respeito à questão dos resíduos sólidos. A começar pelo conceito de resíduos sólidos que no inciso XVI do artigo $3^{\circ}$ da referida norma dispõe:

Art. $3^{\circ}$

$[\ldots]$

XVI - resíduos sólidos: material, substância, objeto ou bem descartado resultante de atividades humanas em sociedade, a cuja destinação final se procede, se propõe proceder ou se está obrigado a proceder, nos estados sólido ou semissólido, 
bem como, gases contidos em recipientes e líquidos cujas particularidades tornem inviável o seu lançamento na rede pública de esgotos ou em corpos d'água, ou exijam para isso soluções técnica ou economicamente inviáveis em face da melhor tecnologia disponível;

Da simples leitura do texto da lei, percebe-se que é um conceito que abrange o subproduto decorrente do processo industrial das usinas sucroalcooleiras e, portanto, deve ser objeto de preocupação do setor industrial. No entanto, é necessário destacar que anteriormente a esta lei já existiam outras leis que tratavam sobre a questão do meio ambiente e sua proteção, tais como a Constituição Federal de 05 de outubro de 1988, que já previa em seu artigo 225 que:

Art. 225. Todos têm direito ao meio ambiente ecologicamente equilibrado, bem de uso comum do povo e essencial à sadia qualidade de vida, impondo-se ao Poder Público e à coletividade o dever de defendê-lo e preservá-lo para as presentes e futuras gerações.

Não se pode deixar de referir que uma específica lei referente a Política Nacional do Meio Ambiente de 1981 já dispõe sobre esse assunto. $\mathrm{O}$ conceito de meio ambiente envolve tanto aspectos biológicos e físicos, quanto aspectos econômicos, sociais e culturais. Fiorillo (2007) apud Medeiros e Gadelha (2016), classifica-o em meio ambiente natural ou físico, meio ambiente cultural, meio ambiente artificial e meio ambiente do trabalho.

Outros conceitos que estão relacionados com a temática do meio ambiente são o de Gestão Ambiental e o de Impacto Ambiental. Para Almeida et al. (2017) a gestão ambiental "pode ser entendida como o conjunto de procedimentos e atividades que objetiva conciliar desenvolvimento com qualidade ambiental" e para Sanches (2008), no sentido comum, impacto ambiental está relacionado a algum dano à natureza.

Segundo Medeiros e Gadelha (2016) a preocupação com o meio ambiente vem ganhando força a cada dia, levando as empresas a dar maior atenção a este tema. Objetiva-se por meio do desenvolvimento sustentável melhorar a qualidade de vida, respeitando a capacidade de suporte dos ecossistemas, diminuindo a miséria, a exclusão social e econômica, do consumismo, do desperdício e da degradação ambiental. Para os mesmos autores, os críticos afirmam inexistir um índice para medi-lo a não ser pelo PIB. Após muitos anos a Organização das Nações Unidas (ONU) criou o Índice de Desenvolvimento Humano (IDH) que fica mais próximo da realidade. A ONU procurará utilizar pesquisas de opinião e outros dados para aproximar o índice da realidade. Não se pode analisar o desenvolvimento econômico da preservação ambiental, o viés ambiental deve ser presente em todas as decisões humanas impactantes (Colombo, 2011).

Outra questão de extrema importância é lembrado por Ribeiro \& Pesquero (2010) no que diz a observância da questão ambiental, que é a queimada no pré-corte da cana-de-açúcar. Pontuam os autores que apenas $25 \%$ da produção brasileira dessa cultura é mecanizada, portanto, estima-se que $75 \%$ da produção ainda é realizada a queima da palha da cana-de-açúcar antes da colheita, sendo que as queimadas prejudicam o meio ambiente. Nem sempre é fácil conciliar os aspectos econômicos, sociais e ambientais como se vê:

"A proibição da queima da cana-de-açúcar para seu despalhamento pré-colheita representa um dilema socioambiental. Ao mesmo tempo que a sua proibição pode contribuir para uma melhoria da qualidade do ar, e, portanto, para a sustentabilidade ambiental e a prevenção de doenças, ela pode suprimir milhares de empregos no campo, gerando insustentabilidade social e espacial" (Ribeiro \& Pesquero 2010).

O mundo está cada vez mais voltado para fontes renováveis de matérias primas, tanto por razões econômicas, ambientais e geopolíticas. A cultura de cana-de-açúcar acarreta impactos tanto ambientais como sociais. Portanto, faz-se necessário que o setor público desenvolva políticas para planejamento, monitoramento e regulamentação do setor. Vale ressaltar a importância da pesquisa acadêmica para viabilizar a dinâmica do setor público e privado com o objetivo de promover a sustentabilidade de um dos setores mais importantes do país (Bastos, 2007; Liboni; Cezarino, 2012). 


\subsection{Impactos Econômicos e da pandemia Covid-19 na Indústria Sucroalcooleira}

Para Guevara et al. (2017), muitas nações estão despertando para produção de etanol de cana-de-açúcar por ser um combustível renovável e de custo menor, também porque a oferta mundial desse biocombustível está em expansão. Segundo esses pesquisadores, as projeções de mudanças climáticas indicam que os sistemas de produção de cana serão afetados por eventos climáticos extremos, pela elevação das temperaturas e aumento de secas.

De acordo com os dados da União das Indústrias de cana-de-açúcar, o Brasil é o maior produtor global de cana-deaçúcar, passando nas últimas décadas por uma revolução tecnológica, extração de novos subprodutos e adoção de práticas sustentáveis. Dados recentes apontam que a quantidade de cana-de-açúcar processada pelas unidades produtoras da região Centro-Sul no ciclo 2020/2021, alcançou 42,93 milhões de toneladas na segunda metade de junho, com uma queda de 7,73\%, ocasionada por fatores climáticos quando comparados com a mesma quinzena do ciclo 2019/2020 (Única, 2020).

Uma publicação recente do novaCana, um dos sites mais acessados do mundo sobre o mercado de etanol e cana-deaçúcar, revela que a pandemia do novo coronavírus (SARS-COV-2) está trazendo efeitos para sociedade e para vários setores econômicos. Isso inclui o setor sucroenergético, em que a safra 2020/21 foi diretamente atingida pela queda na demanda e nos preços dos combustíveis. Devido a consequência deste cenário há um distanciamento das expectativas esperadas no final da temporada anterior (Novacana, 2020).

Com o impacto da pandemia do novo coronavírus pelo mundo e seu consequente isolamento social, restrição na movimentação de pessoas e mercadorias, a demanda por combustíveis diminui, visto que a crise global de saúde impacta diretamente na atividade econômica. Diante desta crise causada pela pandemia da Covid-19 percebe-se que a cadeia produtiva de combustíveis dependerá da duração e intensidade das medidas de isolamento (Losekann \& Rodrigues, 2020).

A crise gerada pela pandemia agravou ainda mais a economia brasileira que já estava fragilizada, tendo um grande impacto na confiança dos investidores e na cadeia produtiva do setor sucroalcooleiro no país. Devido à descapitalização do setor, à queda de eficiência da produção e à baixa produtividade dos canaviais houve uma retração nas vendas no setor de combustíveis (Torquato et al., 2020).

Uma recente publicação da Embrapa afirma que a redução do preço do petróleo no mercado internacional trouxe queda no valor dos combustíveis afetando a competitividade do etanol brasileiro e como consequência as usinas estão reprogramandose para acelerar a produção de açúcar. Devido ao excesso de produção de etanol, muitas usinas estão doando etanol ao sistema público de saúde para produção de álcool em gel a 70\%, usado na desinfecção e antissepsia (Guaraldo \& Seixas, 2020).

De acordo com o último relatório da produção de açúcar da USDA (Departamento de Agricultura dos EUA), apesar dos obstáculos epidêmicos e logísticos da Covid-19 e mesmo com a desvalorização da moeda brasileira comparada ao dólar norte-americano, o produto brasileiro deve se manter altamente competitivo. Dados apontam que provavelmente as exportações de açúcar bruto serão responsáveis por 23,08 milhões de toneladas na safra 2020/21, tendo um aumento significativo em relação à safra anterior 2019/20 (USDA, 2020).

A desaceleração na economia causada pela pandemia da Covid-19, trouxe algumas consequências para o setor, que foram acentuadas pela oscilação do preço do petróleo. Uma negociação com o governo já está em andamento para uma obtenção de crédito para minimizar os efeitos da crise e mudanças deverão ser estruturadas para que se diminuam as incertezas desse período, onde o uso de tecnologias, conhecimento científico e planejamento serão fundamentais (Torquato et al., 2020).

\subsection{Subprodutos da cana e sua utilização}

$\mathrm{Na}$ indústria sucroalcooleira, os subprodutos gerados (Figura 2) por um lado são vistos como poluidores ambientais, mas, também são utilizados como matéria prima para produtos de diversos setores. Isto tem promovido estudos na área acadêmica 
com objetivo de otimizar os processos através de uma interação entre os setores industriais, ambientais e agrícolas visando a utilização correta dos recursos naturais (Primo et al., 2015).

Figura 2. Fluxograma dos subprodutos gerados na produção de bioetanol.

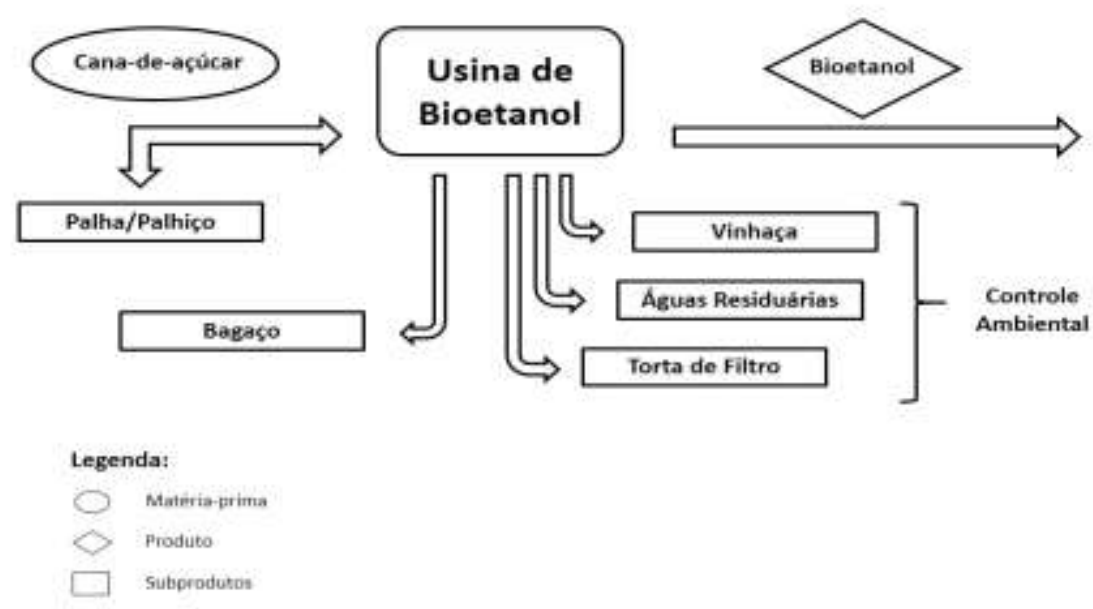

Fonte: Bonassa et al. (2015).

No processamento da cana-de-açúcar os resíduos industriais têm sido amplamente utilizados. Por exemplo, a vinhaça (subproduto originado da produção de etanol) é muito utilizada como fertilizante, a torta de filtro (resíduo resultante da filtração do caldo de cana) como adubo nos canaviais, o bagaço na cogeração de energia elétrica (Gomes et al., 2016). A Tabela 1 mostra, de acordo com dados da Agência Embrapa de Informação Tecnológica (AGEITEC), os principais subprodutos e resíduos, a quantidade gerada e suas principais aplicações. 
Tabela 1. Principais subprodutos e resíduos da cana-de-açúcar.

\begin{tabular}{|c|c|c|}
\hline Subprodutos e resíduos & Quantidade gerada & Principais aplicações \\
\hline Bagaço & $\begin{array}{l}280 \mathrm{~kg} / \text { tonelada de cana } \\
\text { processada }\end{array}$ & $\begin{array}{c}\text { Combustível para caldeira, } \\
\text { produção de celulose e } \\
\text { alimentação de gado confinado }\end{array}$ \\
\hline Torta de filtro & $\begin{array}{c}20 \text { a } 40 \mathrm{~kg} / \text { tonelada de cana } \\
\text { processada }\end{array}$ & Fertilizante \\
\hline Melaço & $\begin{array}{c}40 \text { a } 60 \mathrm{~kg} / \text { tonelada de cana } \\
\text { processada }\end{array}$ & $\begin{array}{l}\text { Produção de proteína, rações, } \\
\text { levedura prensada para } \\
\text { panificação, antibióticos }\end{array}$ \\
\hline Vinhaça & 12 a 18 litros/litro de álcool & $\begin{array}{c}\text { Alimentação de animais, } \\
\text { produção de proteínas } \\
\text { (biomassa), produção de metano } \\
\text { e fertilização de solos }\end{array}$ \\
\hline Óleo fúsel & $\begin{array}{c}0,05 \text { a } 0,2 \text { litros/100 litros de } \\
\text { álcool }\end{array}$ & $\begin{array}{c}\text { Matéria-prima para } \\
\text { processamento de refinação - } \\
\text { solventes } \\
\end{array}$ \\
\hline Álcool bruto & 1 a 5 litros/100 litros de álcool & $\begin{array}{l}\text { Aplicação na produção de } \\
\text { álcoois extrafino e neutro, } \\
\text { combustível }\end{array}$ \\
\hline Levedura seca & $2,5 \mathrm{~kg} / 100$ litros de álcool & Ração animal \\
\hline
\end{tabular}

Fonte: Autores, com dados fornecidos pela AGEITEC.

Nesta revisão foram abordadas algumas aplicações dos subprodutos na indústria alimentícia, na construção civil, na geração de energia elétrica e produção de etanol de segunda geração, conforme ilustrado na Tabela 2.

Tabela 2. Resumo das principais aplicações dos subprodutos da cana-de-açúcar.

\begin{tabular}{|c|c|c|}
\hline Subproduto & Aplicação & Referência \\
\hline Pedaço de cana & Cultura para leite fermentado & $\mathrm{Ng}(2020)$ \\
\hline \multirow[b]{2}{*}{ Bagaço da cana } & Produção de xilitol & Carvalho (2007) \\
\hline & Etanol de segunda geração & $\begin{array}{c}\text { González- Bautista et al. (2020) } \\
\text { Carvalho et al. (2016) } \\
\text { Dias et al. (2013) }\end{array}$ \\
\hline \multirow[b]{2}{*}{ Bagaço da cana + palha da cana } & Geração térmica & Carvalho et al. (2020) \\
\hline & Geração elétrica & $\begin{array}{l}\text { Carvalho et al. (2020) } \\
\text { Dias et al. (2013) }\end{array}$ \\
\hline \multirow[t]{2}{*}{ Melaço + bagaço da cana } & $\begin{array}{l}\text { Substrato para aumentar } \\
\text { eficiência biológica de } \\
\text { cogumelos L. edodes }\end{array}$ & \multirow[t]{2}{*}{ Rossi (2003) } \\
\hline & $\begin{array}{l}\text { Substrato para produção de } \\
\text { cogumelos L. edodes }\end{array}$ & \\
\hline Melaço & $\begin{array}{c}\text { Fonte de carbono para } \\
\text { bioprocessos microbianos }\end{array}$ & Costa et al. (2020) \\
\hline Cinza do bagaço da cana (CBC) & $\begin{array}{l}\text { Confecção de argamassa e } \\
\text { concreto }\end{array}$ & $\begin{array}{l}\text { Avila et al. (2016) } \\
\text { Lopes et al. (2014) }\end{array}$ \\
\hline
\end{tabular}

Fonte: Autores.

\subsection{Indústria de Alimentos}

Existe um interesse crescente em reutilizar resíduos e subprodutos de alimentos de diferentes etapas de processamento, não apenas para garantir a sustentabilidade ambiental, mas também para melhorar o desempenho econômico dos processos (Puertolas, 2016). 
A constante e crescente necessidade de suprimento de matéria-prima para as indústrias e produtos de boa qualidade tem levado ao desenvolvimento de novos produtos obtidos a partir de resíduos que antes eram descartados. Ao serem reaproveitados e inseridos em formulações em que substituem outros ingredientes, os subprodutos podem proporcionar produtos de alto valor nutricional, com características desejáveis, além de gerar valor agregado para as indústrias (Barbosa et al., 2011).

$\mathrm{Ng}$ (2020) utilizando os pedaços de cana-de-açúcar para imobilizar culturas de Kefir LAB, desenvolveu culturas iniciais para a produção de leite fermentado. Seu estudo demonstrou que a cana-de-açúcar tem potencial para indústria alimentícia por ser um ótimo habitat para o Kefir LAB e ser capaz de produzir um leite fermentado estável.

No bagaço de cana-de-açúcar há alta quantidade de xilose. Carvalho (2007) estudou como esse bagaço poderia ser utilizado para a produção de um adoçante: o xilitol. O autor obteve um melhor desempenho na bioconversão para xilitol utilizando levedura Candida guilliermondii FTI 20037 e suplementando os fermentados com nutrientes de baixo custo como sulfato de amônia e/ou extrato de farelo de arroz.

Uma outra forma de uso para os subprodutos da cana-de-açúcar é na forma de substrato para produção cogumelos Lentinula edodes. O bagaço da cana-de-açúcar por ser um meio poroso foi o substrato para o crescimento do cogumelo e a esse sistema foi adicionado o melaço de cana-de-açúcar, um subproduto rico em açúcares o que proporcionou um aumento de $20 \%$ na eficiência biológica desses cogumelos (Rossi, 2003).

Costa et al. (2020) em seu estudo validou a eficácia do uso do melaço como fonte alternativa de carbono para bioprocessos microbianos. O cultivo da levedura Rhodotorula mucilaginosa CCT3892 em melaço aumentou em 74,05\% a biossíntese de ácido graxo (ácido oleico) em comparação ao meio sintético.

\subsection{Produção de etanol de segunda geração (2G)}

O Brasil é o maior produtor de etanol obtido através da cana-de-açúcar, um combustível renovável e ecológico. Várias linhas de pesquisas estudam a possibilidade da produção de etanol de segunda geração (Dias et al., 2009; Cardona et al., 2010; Dias et al., 2012; Santos et al., 2012; Carvalho et al., 2017; Silva \& Serra, 2017), que é produzido principalmente através do bagaço e da palha da cana-de-açúcar, ambos subprodutos compostos de materiais lignocelulósicos que podem ser transformados em álcool. Uma das grandes vantagens de introduzir o etanol de segunda geração é aumentar a quantidade de produção de etanol através da utilização de subprodutos industriais, sem ampliar desta forma a área de cultivo (Kassinoff, 2013).

O etanol de segunda geração é uma alternativa para maior aproveitamento da biomassa da cana, sendo obtido pela quebra dos polissacarídeos (celulose e hemicelulose) com o objetivo de produzir açúcares mais simples para serem utilizados na produção de etanol. Espera-se que o custo da produção de etanol de segunda geração em poucos anos seja mais barato comparando com os de primeira geração. Porém, devem ser feitos investimentos tecnológicos a fim de diminuir o custo da biomassa e dos equipamentos industriais (Martins, 2018).

Martins et al. (2014) fizeram um estudo sobre a produção do etanol de segunda geração a partir do bagaço da cana-deaçúcar e concluíram que o etanol 2G é uma alternativa que proporcionará um desenvolvimento econômico, social e ambiental, visto que o Brasil produz em larga escala a cana-de-açúcar. Os pesquisadores relatam que a tecnologia para produção deste biocombustível deve ser melhor elaborada e pesquisada, pois apesar de possuir um elevado custo ainda é viável pelos benefícios quanto a sustentabilidade e ao fato de se ter matéria prima em grande quantidade, já que o Brasil tem um grande potencial para este "combustível limpo".

Para Araújo et al. (2013), diante da demanda do mercado nacional e internacional por biocombustíveis, com as consequências do aquecimento global e do alto preço do petróleo e seus derivados, o etanol de segunda geração a partir do bagaço da cana-de-açúcar é uma excelente opção. Uma das grandes vantagens da utilização do bagaço está na logística: por se tratar de um subproduto da usina, não há necessidade de implantar uma infraestrutura para coleta e transporte. Para produção 
deste combustível no Brasil, os pesquisadores concluíram que deve haver uma maior articulação entre as universidades, institutos de pesquisa, agências de fomento e as empresas de energia.

Visando a viabilização econômica da produção de etanol $2 \mathrm{G}$, um estudo realizado em uma planta piloto apresentou a avaliação do potencial de geração térmica e elétrica com o objetivo de auto sustentar um sistema integrado de etanol de primeira e segunda geração. Os subprodutos do bagaço e da palha da cana-de-açúcar passaram pelas etapas de pré tratamento e hidrólise enzimática. O resíduo sólido obtido da produção de etanol de segunda geração é rico em lignina e foi acrescentado da palha da cana para produção de energia. A autossuficiência energética da planta foi alcançada usando apenas $36 \%$ da palha de cana do campo, gerando ainda um excedente de $63 \mathrm{kwh}$ de eletricidade por tonelada de cana processada, que pode ser aumentada elevando a porcentagem da palha de cana (Carvalho et al., 2020).

Dias et al. (2013) avaliaram uma biorrefinaria flexível que consiste em usar metade do material lignocelulósico excedente como matéria prima (bagaço e lixo - obtidos durante o processamento e a colheita da cana) para produzir eletricidade ou etanol de segunda geração. Esta flexibilidade permite que quando o preço da eletricidade estiver favorável, o material lignocelulósico pode ser desviado para produzir vapor, ou vice-versa, quando os preços do etanol estiverem mais atraentes. Os pesquisadores concluíram que uma biorrefinaria flexível pode oferecer vantagens tanto econômicas como também ambientais comparado com as biorrefinarias convencionais que possuem uma capacidade de produção fixa.

González-Bautista et al. (2020) estudaram a influência do enriquecimento de levedura e inóculo de Pycnoporus sanguineus na desfenolização do bagaço de cana-de-açúcar para produzir etanol de segunda geração. O objetivo do estudo foi definir as condições do substrato que favorecem a desfenolização no pré-tratamento do bagaço de cana-de-açúcar. As condições definidas pelos pesquisadores para o pré-tratamento com bagaço de cana-de-açúcar foram favorecidas com a adição de altas quantidades de extrato de levedura e baixas quantidades de inóculo e um tempo de incubação de 60 dias de fermentação em estado sólido. A conclusão foi que estas condições de pré-tratamento são benéficas para a seguinte etapa de sacarificação (processo de hidrólise em que o amido é transformado em açúcares fermentáveis) já que a celulose fica mais disponível, contribuindo desta forma para aumentar os rendimentos da produção do bioetanol.

Carvalho et al. (2016) realizaram uma abordagem matemática para otimizar o processo de extração a frio como prétratamento para produção de bioetanol a partir de eucalipto, bagaço e palha de cana-de-açúcar. As condições ideais foram identificadas com base em um experimento com delineamento fatorial resultando na remoção de $52 \%$ e $61 \%$ de xilano e $37 \%$ e $45 \%$ de lignina para o bagaço e a palha da cana respectivamente. O maior rendimento, concentração e produtividade volumétrica de etanol encontrados foram obtidas para a palha de cana-de-açúcar. Os pesquisadores sugerem estudos adicionais para otimizar o tempo do processo de sacarificação e fermentação com o objetivo de melhorar a produção de etanol para biomassas que foram pré- tratadas por extração alcalina a frio.

Gubicza et al. (2016) fizeram uma análise técnico-econômica para um processo simplificado de produção de etanol lignocelulósico a partir do bagaço de cana desenvolvido pela Universidade da Flórida em escalas de laboratório. Os principais contribuintes identificados para o custo foram: o preço da matéria-prima e o custo de material que contribuem com $25 \%$ e $45 \%$ do custo total de produção de etanol, respectivamente. Conforme o modelo apresentado, os pesquisadores concluíram que o custo de produção é financeiramente aceitável usando concentrações mais altas de enzimas, aumentando assim, o rendimento do etanol.

Resolvendo alguns problemas técnicos no processo de produção, as expectativas apontam que o etanol de segunda geração deve tornar-se um paradigma no setor sucroenergético a partir de 2030. O desenvolvimento da rede sócio técnica junto com o aumento dos financiamentos públicos para pesquisa e produção jogam um papel muito importante para formação da rede do etanol celulósico (Lorenzi \& Andrade, 2019). 


\subsection{Construção Civil}

A indústria da construção é um dos setores que mais consome recursos naturais e utiliza energia de forma intensiva, gerando consideráveis impactos ambientais, tendo um papel fundamental na execução dos objetivos globais do desenvolvimento sustentável (Ávila et al., 2016). A utilização pela construção civil de resíduos gerados em outros setores da economia é muito importante não apenas em virtude da redução e disponibilidade de matérias-primas não renováveis, tão necessárias às atividades da construção civil, mas também devido ao aumento da atividade industrial, e ao o aumento da produção dos resíduos de produtos naturais (Savastano \& Warden, 2003).

A preocupação com a preservação do meio ambiente tem incentivado a busca de muitas alternativas para substituição dos agregados naturais ou do cimento com incorporação de certos resíduos na confecção de argamassas e concretos (Macedo, 2009), sendo que um dos resíduos que podem ser utilizados é a cinza do bagaço de cana (CBC). No processo de produção do complexo sucroalcooleiro gera-se como resíduo o bagaço, utilizado na geração de energia por meio da queima em caldeiras, restando ao final, cinzas residuais do bagaço da cana-de-açúcar (CBC), geralmente lançadas ao meio ambiente de forma inadequada (Lima et al., 2010).

Constituída basicamente de sílica, que é um composto químico com potencial pozolânico, a cinza do bagaço de cana (CBC) torna-se um material com grande potencial para ser usada como adição mineral, substituindo parte do cimento na confecção de argamassas e concretos (Ávila et al., 2016; Cordeiro et al., 2008). Materiais pozolânicos são materiais silicosos ou sílico aluminosos que possuem pouca ou nenhuma atividade aglomerante, sendo que na presença de água reage com hidróxido de cálcio à temperatura ambiente para formar compósitos com propriedades aglomerantes, podendo ser naturais ou artificiais (NBR 12653, 2015).

Segundo trabalho de Ávila et al. (2016) o concreto com 10\% de substituição de cimento por CBC é o que apresenta melhores resultados, podendo ser utilizado em concretos onde não seja necessária uma resistência muito elevada. A obtenção de cinzas com maiores teores de sílica reativa, principalmente por meio de procedimentos de queima melhor ajustados, pode permitir maiores teores de substituição ou melhorias mais significativas nas propriedades físicas e mecânicas das argamassas (Paula et al., 2009).

A utilização das cinzas de bagaço de cana, podem ser usadas para substituir parcialmente a massa do cimento em uma proporção de $10 \%$ para que a resistência à compressão não seja afetada. Esse acréscimo de CBC nos cimentos parecem promissores, mas ainda devem ser realizados estudos mais aprofundados para confirmar sua viabilidade técnica e econômica deste resíduo para sua utilização como material de construção (Lopes et al., 2014).

\subsection{Produção de energia elétrica}

O setor sucroalcooleiro já tem a preocupação de realizar atividades de produção mais limpa com a cogeração de energia a partir do bagaço de cana que está inserido nesse contexto, além de ajudar na preservação do meio ambiente. O potencial de geração de energia a partir do bagaço de cana-de-açúcar brasileiro equivale a 25 mil giga watts/hora. Tal potencial equivale a 5,4\% dos 461.029 GW/h gerados no ano de 2006 por todas as fontes energéticas do país (Simões, 2020).

A energia gerada a partir do bagaço/palha da cana-de açúcar apresenta como vantagem, a diminuição da falta de energia em virtude de uma seca prolongada, uma vez que a matriz energética do Brasil é na sua maioria hidroeletricidade (Leme, 2005), além de outros benefícios, o aproveitamento do resíduo, sua disponibilização em grande quantidade, o fácil processamento, o baixo custo se comparado com a construção de hidrelétricas que causam enorme degradação ambiental (Galbiati et al., 2010).

A produção elétrica nas usinas de açúcar e álcool em sistemas de cogeração, que usam o bagaço de cana como combustível, é muito utilizada neste segmento em todo o mundo. O que diferencia seu uso é a eficiência com que o potencial do 
bagaço de cana é aproveitado. A geração de energia elétrica por biomassa da cana deve crescer nos próximos anos no Brasil (Corrêa Neto, 2001).

A cogeração de energia elétrica pelas indústrias sucroalcooleiras torna-se uma alternativa viável para complementar a oferta de energia hidráulica, ressaltando a importância da biomassa e de seu potencial energético (Eid et al., 1998). O sistema de cogeração de energia se apresenta como uma solução para a crise de energia enfrentada pelo nosso país e como uma opção para minimização dos problemas ambientais e sociais provenientes dos setores energéticos, que são o aquecimento global e o fornecimento de energia sustentável (Galbiati et al., 2010).

\section{Considerações Finais}

Diante da relevância da cultura de cana-de-açúcar em todo território nacional e internacional, e consequentemente com os estudos sobre o tema visando a melhoria do processo, o presente estudo teve como objetivo mostrar os impactos ambientais, econômicos e sociais que geram as indústrias sucroalcooleiras. Também irá apresentar vários estudos relevantes que buscam de forma sustentável destinar os subprodutos gerados pelas indústrias.

Com relação aos impactos sociais, vale salientar que as indústrias de produção de açúcar e etanol promovem a geração de empregos diretos e indiretos, também é responsável por uma relevante parcela do PIB das regiões onde estão inseridas, todavia, é necessário um olhar com maior critério aos impactos sociais gerados. É relevante ressaltar que o trabalho empregado no corte da cana ainda é um trabalho físico desgastante e penoso, embora essa modalidade de trabalho venha sendo substituída pela mecanização, que por sua vez gera empregos mais qualificados e com maiores remunerações.

No que tange aos impactos econômicos, é possível verificar a importância que a cultura da cana-de-açúcar traz para a economia brasileira, porém, vale ressaltar os dados recentes que devido a pandemia do novo coronavírus, o setor sucroalcooleiro está sofrendo um impacto direto em seu faturamento e isto poderá trazer grandes dificuldades ao setor.

Percebe-se que os resíduos gerados no setor sucroalcooleiro podem se tornar um impasse ambiental se não são bem destinados, no entanto, se bem utilizados podem trazer mais lucros e diminuição dos problemas ambientais. Para isso, é necessário maior investimento do setor público e privado, e um aumento nas pesquisas acadêmicas, pois a utilização dos subprodutos é altamente promissora para o desenvolvimento sustentável.

Dessa forma, este trabalho pode contribuir com estudos futuros como um instrumento para instigar a investigação da sustentabilidade na cadeia da cana-de-açúcar, seja na produção de alimentos, ou na produção de energia. Vale ressaltar que esta revisão não destacou como as empresas ligadas ao setor sucroalcooleiro estão ajudando o país para o cumprimento das metas relacionadas aos Objetivos de Desenvolvimento Sustentável. Também há lacunas sobre os aspectos do setor, ligados aos fatores econômicos, sociais e ambientais, além de haver espaço para estudar os impactos que esse segmento da economia gera nas regiões do cultivo, onde há empregos com baixas remunerações e levando muitas famílias a utilizar o sistema público como educação e saúde.

\section{Agradecimentos}

Esta pesquisa só foi possível graças ao apoio do Programa de Pós-Graduação em Sustentabilidade (PSU), mestrado acadêmico na modalidade associado entre o Instituto Federal do Paraná e a Universidade Estadual de Maringá - Campus Umuarama - Paraná, que incentivam à pesquisa científica e o aprimoramento de seus discentes.

O presente trabalho foi desenvolvido com apoio da Coordenação de Aperfeiçoamento Pessoal de Nível Superior Brasil (CAPES) - Código de Financiamento 001. 


\section{Referências}

AGEITEC - Agência Embrapa de Informação Tecnológica (2020). Árvore do conhecimento Cana-de-açúcar. https://www.agencia.cnptia.embrapa.br/gestor/cana-de-acucar/arvore/CONTAG01_108_22122006154841.html\#.

Almeida, A. N., Xavier, E. M., Couto Junior, A. F. \& Vieira, L. C. G. (2017). Efetividade da Compensação Ambiental Monetária no Brasil. Floresta e Ambiente. 24, e20150116.

Aquino, A. F., Bidô, É. S., Galvão, M. L. M. \& Oliveira, V. N. (2014). O etanol da cana de açúcar: possibilidades energéticas da região de Ceará-Mirim-RN. Holos, 01,105-125.

Araújo, G. J. F., Navarro, L. F. S. \& Santos, B. A. S. (2013). O etanol de segunda geração e sua importância estratégica ante o cenário energético internacional contemporâneo. Fórum Ambiental da Alta Paulista, 9(5) 01-11.

Associação Brasileira De Normas Técnicas (2015). NBR 12653: Materiais Pozolânicos - Requisitos. 4, 2015.

Ávila, T. C., Fernandes, S. E. \& Akasaki, J. L. (2016). A influência da substituição de cimento por cinza do Bagaço de cana de açúcar (CBC) em concretos. Revista Cientifica ANAP Brasil, 9(17), 35-46.

Barbosa, A. P. P. L. \& Junior, W. G. (2012). Cenários tecnológicos para a demanda por cana de açúcar. Future Studies Research Journal. 4(1), 92-113.

Barbosa, J. R., Beltrame, S. C., Bragatto, M. M., Débia, P. J. G., Bolanho, B. C. \& Danesi, E. D. G. (2011). Avaliação da composição e dos parâmetros tecnológicos de farinhas produzidas a partir de subprodutos agroindustriais. Revista Tecnológica, 21-28.

Bastos, V. D. (2020). Etanol, alcoolquímica $e \quad$ biorrefinaria. $\quad$ B-38. https://web.bndes.gov.br/bib/jspui/bitstream/1408/2527/1/BS\%2025\%20Etanol\%2c\%20Alcoolqu\%c3\%admica\%20e\%20Biorrefinarias_P.pdf.

Bonassa, G., Schneider, L. T., Frigo, K. D. A., Feiden, A., Teleken, J. G. \& Frigo, E. P. (2015). Subprodutos gerados na produção de bioetanol: bagaço, torta de filtro, água de lavagem e palhagem. Revista Brasileira de Energias Renováveis, 4, 144-166.

Brasil (1981). Lei n ${ }^{\circ}$ 6.981, de 31 de agosto de 1981. Dispõe sobre a Política Nacional do Meio Ambiente, seus fins e mecanismos de formulação e aplicação, e dá outras providências. Brasília, DF: Presidência da República. http://www.planalto.gov.br/ccivil_03/LEIS/L6938.htm. Acesso em: 21 jul. 2020.

Brasil (Constituição 1988). Constituição da República Federativa do Brasil de 1988. Brasília, DF: Presidência da República. http://www.planalto.gov.br/ccivil_03/Constituicao/Constituicao67.htm.

Brasil (2010). Lei n 12.305 , de 2 de agosto de 2010. InstCardona, C. A., Quintero, J. Á. \& Paz, I. C. (2010). Production of bioethanol from sugarcane bagasse: Status and perspectives. Bioresource Technology, 101, 4754-4766.

Carvalho, D. J., Moretti, R. R., Colodette, J. L. \& Bizzo, W. A. (2020). Assessment of the self-sustained energy Generation of na integrated first and second generation ethanol production from sugarcane through the characterization of the hydrolysis process residues. Energy Conversion and Management, $203,112267$.

Carvalho, D. M., Sevastyanova, O., Queiroz, J. H. \& Colodette, J. L. (2016). Cold alcaline extraction as a pretreatment for bioethanol production from eucalyptus, sugarcane bagasse and sugarcane straw. Energy Conversion and Management, 124, 315-324.

Carvalho, J. L. N., Nogueirol, R. C., Menandro, L. M. S., Bordonal, R. O., Borges, C. D., Cantarella, H. \& Franco, H. C. J. (2017). Agronomic and environmental implications of sugarcane straw removal: a major review. Global Change Biology Bioenergy, 9, 1181-1195.

Carvalho, L. C., Bueno, R. C. O. F., Carvalho, M. M., Favoreto, A. L. \& Godoy, A. F. (2013). Cana-de-açúcar e álcool combustível: histórico, sustentabilidade e segurança energética. Enciclopédia Biosfera, 9(16), 530-542.

Carvalho, W., Canilha, L. \& Silva, S. S. (2007). Semi-continuos xylitol bioproduction in sugarcane bagasse hydrolysate: effect of nutritional supplementation. Revista Brasileira de Ciências Farmacêuticas, 43(1), 47-53.

Castaldelli, V. N., Castro, J. N. T., Quevedo, V. R. B., Akasaki, J. L., Tashima, M. M \& Bernabeu, J. P. (2010). Avaliação da cinza do bagaço da cana-de-açúcar (in natura) quando adicionado ao concreto. In: 52 Congresso Brasileiro do Concreto, Fortaleza, CE. Avaliação da cinza do bagaço da cana-de-açúcar (in natura) quando adicionado ao concreto, 1-15.

Colombo, Silvana. (2020). A Responsabilidade Civil Objetiva do Direito Ambiental. Instituto de Ciências Sociais Aplicadas, 4(2), 63-69.

Cordeiro, G. C., Toledo Filho, R. D., Fairbairn, E. M. R. \& Tavares, L. M. M. (2008). Pozzolanic activity and filler effect of sugarcane bagasse ash in Portland cement and lime mortars. Cement \& Concrete Composites, 30(5), 410-418.

Corrêa Neto, V. (2001). Análise de viabilidade da cogeração de energia elétrica em ciclo combinado com gaseificação de biomassa de cana-de-açúcar e gás natural. Dissertação de Mestrado em Ciências em Planejamento Energético. Rio de Janeiro, RJ, Brasil.

Costa, W. A., Padilha, C. E. A., Junior, S. D. O., Silva, F. L. H., Silva, J., Alcântara, M. A., Ferrari, M. \& Santos, E. S. (2020). Oil-lipids, carotenoids and fatty acids simultaneous production y Rhodotorula mucilaginosa CCT3892 using sugarcane molasses as carbon source. Brazilian Journal Food Technology, 23(22), $1-11$.

Dias, M. O. S., Junqueira, T. L., Cavalett, O., Pavanello, L. G., Cunha, M., Jesus, C. D. F., Maciel Filho, R. \& Bonomi, A. (2013). Biorefineries for the production of first and second generation etanol and electricity from sugarcane. Applied Energy, 109, 72-78.

Dias, M. O. S., Ensinas, A. V., Nebra, A. S., Maciel Filho, R., Rossell, C. E. V. \& Maciel, M. R. W. (2009). Production of bioethanol and other bio-based materials rom sugarcane bagasse: Integration to conventional bioethanol production process. Chemical Engineering Research and Design, 87, $1206-1216$. 
Dias, M. O. S., Junqueira, T. L., Jesus, C. D. F., Rossell, C. E. V., Maciel Filho, R. \& Bonomi, A. (2012). Improving second generation etanol production through optimization of first generation production process from sugarcane. Energy, 43, 246-252.

Eid, F., Chan, K. \& Pinto, S. S. (1998). Tecnologia e co-geração de energia na indústria sucroalcooleira paulista: uma análise da experiência e dificuldades de difusão. Informações Econômicas, 28(5), 36-47.

Filho, M. A. (2007). Colhedora de cana preserva emprego e reduz desperdício. http://www.unicamp.br/unicamp/unicamp_hoje/ju/julho2007/ju365pag05.html.

Galbiati, J. K., Gallo, C. A. \& Lavanholi, M. G. P. (2010). Produção de energia elétrica a partir da queima do bagaço de cana-de-açúcar. Nucleus, 7(1), 127-138.

Gomes, A. C. A., Meurer, A. P. S. \& Pintor, G. M. Z. (2016). O uso da logística reversa para atender a responsabilidade socioambiental: estudo de caso em uma agroindústria canavieira no Paraná. Revista Orbis Latina 6(2), 111-128.

González-Bautista, E., Alarcón-Gutierrez, E., Dupuy, N., Gaime-Perraud, I., Ziarelli, F. \& Farnet-Da-Silva, A. M. (2020). Influence of yeast extract enrichment and Pycnoporus sanguineus inoculum on the dephenolisation of sugar-cane bagasse for production of second-generation etanol. Fuel, 260, 116370.

Guaraldo, M. C. \& Seixas, M. A. (2020). Embrapa divulga estudo sobre tendências e novos desafios do agro com a Covid-19. https://www.embrapa.br/buscade-noticias/-/noticia/51932081/embrapa-divulga-estudo-sobre-tendencias-e-novos-desafios-do-agro-com-a-covid-19.

Gubicza, K., Nieves, I. U., Sagues, W. J., Barta, Z., Shanmugam, K. T. \& Ingran, L. O. (2016). Techno-economic analysis of etanol production from sugarcane bagasse using a Liquefaction plus Simultaneous Saccharification and co-Fermentation process. Bioresource Technology, 208, 42-48.

Guevara, A. J. H., Silva, O. R., Hasegawa, H. L., Venanzi, D. (2017). Avaliação de Sustentabilidade da produção de etanol no Brasil: um modelo e dinâmica de sistemas. Brazilian Business Review, 14(4), 435-447.

Henkes, S. L. A. (2009). Responsabilidade civil no Direito Ambiental Brasileiro. Revista de Direito Sanitário, 10(1), 51-70.

Jornalcana. Setor sucroenergético representa $2 \%$ do PIB brasileiro, afirma diretor do ITC. (2019). https://jornalcana.com.br/setor-sucroenergetico-representa2-do-pib-brasileiro-afirma-diretor-do-itc/.

Kassinoff, F. (2013). Uso de bagaço da cana abre novas possibilidades. https://www.unifesp.br/reitoria/dci/edicoes-anteriores-entreteses/item/2280-uso-debagaco-da-cana-abre-novas-possibilidades.

Leme, R. M. (2005). Estimativa das emissões de poluentes atmosféricos e uso de água na produção de eletricidade com biomassa de cana-de-açúcar. Dissertação de Mestrado, Unicamp, Campinas, Brasil.

Liboni, L. B. \& Cezarino, L. O. (2012). Impactos sociais e ambientais da indústria da cana-de-açúcar, Future Studies Reseasch Journal, 4(1), $202-230$.

Lima, A. S., Sales, A., Moretti, J. P. \& Santos, T. J. (2010). Análise de argamassas confeccionadas com a cinza do bagaço da cana-de-açúcar em substituição ao agregado miúdo. Revista Tecnológica, 11(2), 87-97.

Lopes, B. C. S., Britto, A. F. S., Sarmento, A. P. \& Delalibera, R. G. (2014). Análise da viabilidade da utilização da cinza de bagaço de cana-de-açúcar como substituição parcial do cimento Portland. Revista Eletrônica de Engenharia Civil, 9(3), 32-40.

Lorenzi, B. R., Andrade, T. H. N. (2019). O etanol de segunda geração no Brasil: políticas e redes sócio técnicas. Revista Brasileira de Ciências Sociais, 34(100), $1-19$.

Losekann, L. \& Rodrigues, N. (2020). O impacto da Covid-19 no mercado brasileiro de combustíveis. https://petroleohoje.editorabrasilenergia.com.br/impactoda-covid-19-no-mercado-brasileiro-de-combustiveis/

Macedo, P. C. (2009). Avaliação do desempenho de argamassas com adição de cinza do bagaço de cana-de-açúcar. Dissertação de Mestrado, Universidade Estadual Paulista, Ilha Solteira, São Paulo, Brasil.

Machado, P. G., Duft, F. G., Picoli, M. C. A. \& Walter, A. (2014). Diagnóstico da expansão da cana-de-açúcar: aplicação do Barômetro da Sustentabilidade nos municípios de Barretos e Jaboticabal (SP), Revista Sustentabilidade em Debate, 5(1), 13-28.

Martins, C. Z. (2018). Avaliação da produção de etanol de segunda geração (2018). Trabalho de conclusão de curso (graduação em engenharia química), Universidade Federal de Uberlândia, Minas Gerais, Brasil.

Martins, F. A., Martim, T., Correa, A. M. \& Oliveira, F. F. (2014). A produção de etanol de segunda geração a partir do bagaço da cana-de-açúcar. Revista Latino-Americana de Inovação e Engenharia de Produção, 2(3), 5-16.

Medeiros, R. F. \& Gadelha, H. S. (2016). O desenvolvimento sustentável na gestão do meio ambiente. Informativo Técnico do Seminário, 10(1), 32-37.

Neto, J. B. S. S., Soares, P. F., Vanderlei, R. D., Coelho, T, M \& Aragão, F. V. (2014). Inovação no uso de resíduo da indústria sucroalcooleira. Revista Gestão, Inovação e Tecnologia, 4(5), 1536-1549.

Ng, K., Wang, S \& Chen, M. (2020). A novel immobilized cell system involving Taiwanese Kefir microorganisms and sugar cane pieces for fermented milk production. Journal Dairy Science Association, 103, 141-149.

Novacana (2020). Custo de Produção da cana-de-açúcar por hectare cai 6,2\% na safra 2019/20: preço do diesel, dos insumos e da matéria-prima de terceiros têm grande influência sobre o valor gasto pelas usinas. https://www.novacana.com/n/cana/mercado/custo-producao-cana-de-acucar-hectare-cai-6-2-safra-201920-020720. 
Oliveira, E. G., Ferreira, M. E. \& Araújo, F. M. (2012). Diagnóstico do uso da terra na região centro-oeste de Minas Gerais, Brasil: a renovação da paisagem pela cana-de-açúcar e seus impactos socioambientais. Sociedade \& Natureza, 24(3), 545-556.

Paula, M. O., Tinoco, I. F. F., Rodrigues, C. S., Silva, E. N. \& Souza, C. F. (2009). Potencial da cinza do bagaço da cana-de-açúcar como material de substituição parcial de cimento Portland. Revista Brasileira de Engenharia Agrícola e Ambiental, 13(3), 353-357.

Pereira, A. S., Shitsuka, D. M., Parreira, F. J., \& Shitsuka, R. (2018). Metodologia da pesquisa científica. [e-book]. Santa Maria. Ed (pp. 3-9). UAB/NTE/UFSM. https://repositorio. ufsm. br/bitstream/handle/1/15824/Lic_Computacao_Metodologia-Pesquisa-Cientifica. pdf.

Primo, D. A., Silva, k. C., Ramari, T. O. I. \& Ribeiro, R. M., \& Gasparotto, F. (2015). Caracterização do setor sucroalcooleiro no Brasil: produção, produtividade e subprodutos. In: IX EPCC - Encontro Internacional de Produção Científica UniCesumar, 9. Anais eletrônico. Maringá: UniCesumar. p. 4-8.

Puértolas, E. \& Barba, F. J. (2016). Electrotechnologies applied to valorization of by-products from food industry: Main findings, energy and economic cost of their industrialization. Food anda Bioproducts Processing, 100, 172-184.

Pugliese, L. \& Lourencetti, C. (2017). Impactos ambientais na produção do etanol brasileiro: do campo à indústria. Revista Brasileira Multidisciplinar - REBRAM 20(1), 143-165

Ribeiro, H. \& Pesquero, C. (2010). Queimadas de cana-de-açúcar: Avaliação de efeitos na qualidade do ar e na saúde respiratória de crianças. Estudos Avançados. 24(68), 255-271.

Rossi, I. H. \& Monteiro, A. C. (2003). Produção de shiitake (Lentinula edodes) em substrato esterilizado, elaborado à base de bagaço de cana-de-açúcar, suplementado com farelo de arroz e melado de cana-de-açúcar. Revista Brasileira de Microbiologia, 34(1).

Sánchez, L. E. (2008). Avaliação de impacto ambiental: conceitos e métodos. Oficina de Textos, $2,29$.

Santos, F. A., Queiróz, J. H., Colodette, J.L., Fernandes, S. A., Guimarães, V. M. \& Rezende, S. T. (2012). Potencial da palha de cana-de-açúcar para produção de etanol. Química Nova, 35(5), 1004-1010.

Santos, M. P., Klabundi, D. P., Ferreti, K. \& Gonçalves Junior, A. C. (2016). Meio Ambiente: Impactos Ambientais. Scientia Agraria Paranaensis, 15(1), 1-4.

Savastano, J. R. H. \& Warden, P.G. (2003). Special theme issue: Natural fibre reinforced cement composites. Cement \& Concrete Composites, 25(5), 517-624.

Scheuer, J. M. \& Neves, S. M. A. S. (2017). Implicações para o bioma pantanal do cultivo da cana-de-açúcar na bacia do alto Paraguai. Brazilian Geographical Journal: Geosciences and Humanities research médium, 8(2), 36-51.

Silva, R. B. R. \& Serra, J. C. V. (2017). Revisão de biomassas para produção de etanol de segunda geração. Engenharia Ambiental, 14(1), 16-25.

Simões, J. (2008). Aproveitamento da energia gerada com bagaço depende de estímulo. Inovação Unicamp. http://www.inovacao.unicamp.br/etanol/report/newsenergia_bagaco080225.php.

Torquato, S. A., Sachs, R. C. C. \& Nachiluk, K. (2020). Impactos da pandemia e oscilações da cotação do barril de petróleo na cadeia produtiva da cana-deaçúcar no Brasil. http://www.iea.sp.gov.br/ftpiea/AIA/AIA-47-2020.pdf

Única. (2020). Moagem de cana-de-açúcar totaliza 42,93 milhões de toneladas na segunda quinzena de junho. https://unica.com.br/noticias/unica-safra/.

USDA. (2020). United States Department of Agriculture. Sugar exports - complemente to the sugar annual report. http://usdabrazil.org.br/pt-br/reports/sugarannual-2020-complement.pdf. 